\title{
Uma proposta do ensino de croquis para levantamentos topográficos
}

\author{
A proposal for teaching sketches for topographic surveys
}

Recebido: 28/03/2019 | Revisado: 11/02/2020 | Aceito: 12/03/2021 | Publicado: $16 / 06 / 2021$

Évelin Moreira Gonçalves ORCID: https://orcid.org/0000-00032196-4725

Instituto Federal de Educação, Ciência e Tecnologia de Santa Catarina

E-mail: evelin.goncalves@ifsc.edu.br

Priscila Juliana da Silva

ORCID: https://orcid.org/0000-0002-

1672-6143

Instituto Federal de Educação, Ciência e

Tecnologia de Santa Catarina

E-mail: priscila.silva@ifsc.edu.br

Como citar: GONÇALVES, M. E.;

SILVA, P. J.; Uma proposta do ensino de croquis para levantamentos

topográficos. Revista Brasileira da Educação Profissional e Tecnológica, [S.I.], v. 1, n. 20, p. e8460, jun. 2021. ISSN 2447-1801.

This work is licensed under a Creative Commons Attribution 4.0 Unported License.

\begin{abstract}
Resumo
A proposta deste artigo está pautada nos conceitos de aprendizagem significativa a partir da teoria de David Ausubel. Desenvolveu-se atividades pedagógicas a partir da integração entre as unidades curriculares de Desenho Técnico Aplicado à Topografia e Desenho Assistido por computador do curso Técnico em Agrimensura ofertado pelo Instituto Federal de Santa Catarina. O objetivo dessas atividades foi provocar o olhar do estudante para as relações espaciais e aplicações do Croqui dentro da Topografia. Assim, por meio de uma pesquisa-ação, de natureza aplicada e de caráter qualitativo, realizou-se a coleta de dados com observações participantes e a realização de grupos focais.
\end{abstract}

Palavras-chave: Educação Profissional e Tecnológica. Topografia. Croqui. Aprendizagem Significativa.

\begin{abstract}
The proposal of this article is based on the concepts of significant learning from the theory of David Ausubel. Pedagogical activities were developed from the integration between curricular units of Technical Drawing Applied to Surveying and Computer Aided Design of the Technical Course in Surveying offered by the Federal Institute of Santa Catarina. The objective of these activities was to provoke the student's view of the spatial relations and applications of the sketch within Surveying. Thus, by means of an actionresearch, with qualitative and applied characteristics, data collection was carried out with observations and group interviews.
\end{abstract}

Keywords: Professional and Technological Education. Surveying engineering. Sketch. Meaningful Learning. 


\section{INTRODUÇÃO}

$\mathrm{Na}$ expressão livre, os desenhos surgem a partir da manifestação da criatividade, exteriorização das emoções, expressividade da imaginação e habilidades do artista. Já na forma técnica, o desenho ao ser produzido é amparado por instrumentos e normas e podem ser encontrados em projetos, das mais diversas áreas tecnológicas.

A unidade curricular (UC) de Desenho Técnico Aplicado a Topografia (DET) do curso Técnico de Agrimensura do Instituto Federal de Santa Catarina (IFSC) tem como principal objetivo explorar os conhecimentos básicos do Desenho Técnico, através de suas normas técnicas e da utilização de instrumentais ditos não digitais ${ }^{1}$, para que os estudantes desenvolvam habilidades de observação, compreensão e abstração do espaço topográfico, tornando-se capazes de aplicar as técnicas do desenho, principalmente nas operações de campo.

Há, portanto, uma dificuldade de realização das atividades práticas nessa disciplina no que diz respeito à abstração espacial e o relacionamento entre 0 elemento real e sua representação gráfica, em razão da necessidade de se manter as características do ambiente de forma autêntica. Essa dificuldade é percebida na principalmente na realização dos croquis, uma etapa de fundamental importância nos levantamentos topográficos.

Até então esse tema foi abordado na UC de maneira expositiva, seguido de atividades práticas em que os discentes são levados a realizar, dentro dos padrões necessários a topografia, croquis de ambientes externos a sala de aula. No entanto, a relação entre a paisagem e sua representação gráfica no sentido de observar os objetos de levantamento e abstração do que é relevante a representação ficava a cargo dos mesmos. Neste sentido, teorias de aprendizagem, como a aprendizagem significativa proposta por Ausubel, podem ser importantes respaldos no desenvolvimento de recursos didáticos que promovam a aprendizagem de forma concisa, ou seja, que explore as habilidades cognitivas dos estudantes em seu potencial.

Nesta perspectiva é interessante avaliar se estratégias didáticas baseadas na aprendizagem significativa podem contribuir com o processo da internalização dos conceitos necessários ao desenho topográfico. Por isso define-se como objetivo geral desta pesquisa: Desenvolver e analisar atividades pedagógicas planejadas de forma interdisciplinar e com fundamentos na teoria da aprendizagem significativa para 0 desenvolvimento das relações espaciais e suas aplicações no desenho técnico topográfico.

\footnotetext{
${ }^{1}$ Instrumentos ditos não digitais: conjunto tradicional de ferramentas de desenho que auxiliam o ato cinestésico de desenhar à mão.
} 


\section{FUNDAMENTAÇÃO TEÓRICA}

\subsection{CROQUI PARA LEVANTAMENTOS TOPOGRÁFICOS}

O dicionário Aurélio (2002) define o croqui como sendo o delineamento inicial de uma obra de desenho, ou esboço. Há, no entanto, o entendimento de esboço como sendo algo de caráter e de importância temporária, ou seja, uma obra ainda não finalizada. Esse entendimento não deve ser associado ao croqui utilizado nos levantamentos topográficos, pois este tem fundamental relevância para além do processo de produção das plantas topográficas, enquanto recurso para interpretação dos dados e registros de campo complementares que podem ser consultados a qualquer tempo.

Das etapas de levantamentos topográficos o croqui se configura como primordial ao desenvolvimento das plantas topográficas:

Durante a execução de um levantamento de detalhes é importante elaborar um croqui da área que está sendo levantada, associando um nome ou número a cada feição ou ponto levantado, é a mesma indicação deve ser utilizada na caderneta de campo. Isto visa facilitar a elaboração do desenho final (VEIGA, ZANETTI e FAGGION, 2012, p.165).

Ainda segundo Veiga, Zanetti e Faggion (2012), o desenho da área levantada será efetuado a partir dos dados medidos e do croqui elaborado em campo. Durante a etapa do desenho esse croqui desempenha um papel fundamental, pois é por meio dele que se saberão quais pontos serão unidos e o que representam.

Os dados de levantamento de campo devem, segundo a ABNT (NBR 13133, 1994), ser registrados, em cadernetas apropriadas, de forma clara, ordenada, completa, precisa e impessoal. Além disso, ela deve conter croquis dos detalhes a representar, com indicação dos pontos visados e medições complementares de distâncias destinadas a servir de verificação, ou mesmo, para completar o levantamento. A boa ordenação dos elementos coletados no campo é indispensável aos cálculos e desenho da planta que podem ser efetuados por profissionais diferentes.

Tendo em vista a relevância atribuída à execução do croqui nas atividades práticas do profissional de Agrimensura, o mesmo é um tópico fundamental a ser trabalhado nos cursos técnicos desta área. Este tema é geralmente tratado nas unidades curriculares de Desenho Técnico e/ou Topografia, de modo essencialmente prático. O objetivo dessas unidades curriculares é desenvolver a habilidade de representação do espaço físico decorrente da interpretação e abstração dos elementos topográficos de interesse. 


\subsection{AULAS PRÁTICAS E RECURSOS DIDÁTICOS}

Tratando-se do desenvolvimento e da elaboração das formas de abordagem de conteúdo de uma unidade curricular com currículo amplamente direcionado as experiências técnicas práticas, os recursos didáticos e as formas de interação com este conteúdo merecem especial atenção e devem ser direcionados à aprendizagem. "Aprender no e pelo trabalho acontece quando os alunos realizam obras às quais conferem significado" (BARCELOS; ALLAIN e WOLLINGER,2017, p.6).

Neste processo a compreensão, armazenamento e uso da informação quando estimulado através da associação do novo conteúdo a estruturas cognitivas previamente adquiridas é muito mais significativo.

A teoria da aprendizagem de David Ausubel traz como conceito central a aprendizagem significativa, em que, à medida que o novo conteúdo é incorporado às estruturas de conhecimento de um estudante adquire um significado para ele a partir da relação com seu conhecimento prévio.

\subsection{AULAS PRÁTICAS E RECURSOS DIDÁTICOS}

Aprendizagem significativa foi uma teoria formulada inicialmente pelo psicólogo norte americano David Paul Ausubel que publicou seus primeiros estudos a este respeito em 1963 (The Psychology of Meaningful Verbal Learning) e o desenvolveu durante as décadas de 1960 e 1970. As ideias de Ausubel, cujas formulações iniciais são dos anos 60 , se encontram entre as primeiras propostas psicoeducativas em sua obra "Psicologia Educacional", recebendo colaborações em 1980 de Joseph Donald Novak e Helen Hanesian, acerca de fatores sociais, cognitivos e afetivos na aprendizagem (BRUM, 2014).

A aprendizagem significativa segundo seus precursores é uma reorganização clara da estrutura cognitiva, um processo por meio do qual uma nova informação relaciona-se, de maneira substantiva (não-literal) e não-arbitrária, a um aspecto relevante da estrutura de conhecimento do indivíduo, ou seja, relaciona-se com aquilo que o aprendiz já sabe. Substantiva quer dizer não-literal, não ao pé-da-letra, e nãoarbitrária significa que a interação não é com qualquer ideia prévia, mas sim com algum conhecimento especificamente relevante já existente na estrutura cognitiva. Os novos conhecimentos adquirem significado para o sujeito e os conhecimentos prévios adquirem novos significados ou maior estabilidade (MOREIRA, 2010).

O contraponto da aprendizagem significativa é a aprendizagem mecânica, aquela praticamente sem significado, puramente memorística, simplesmente incorporada na estrutura cognitiva de maneira arbitrária e não substantiva. 
Figura 1: Esquemática do contínuo aprendizagem significativa e mecânica

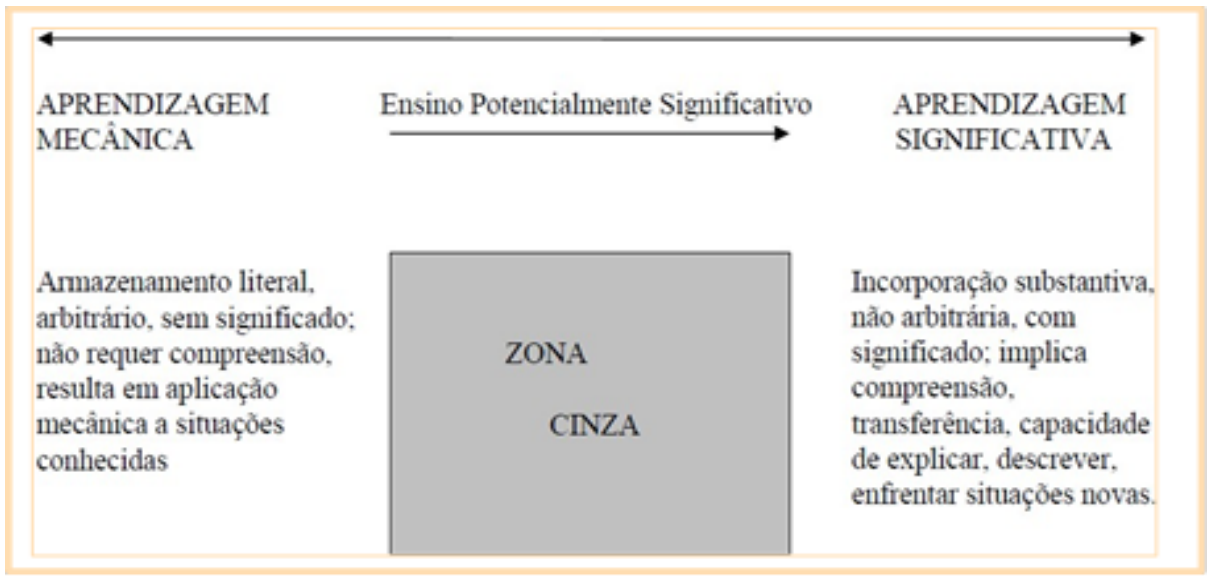

Fonte: Moreira, Mapas conceituais e aprendizagem significativa, 2010

A figura 1 apresentada por Moreira (2010) traz uma visão esquemática do contínuo aprendizagem significativa e mecânica, sugerindo que na prática grande parte da aprendizagem ocorre na zona intermediária desse contínuo e que um ensino potencialmente significativo pode facilitar a transição pela zona cinza. Para tanto é preciso entender como ocorre a aprendizagem significativa e quais os recursos instrucionais capazes de facilitá-la nesta transição.

Traçando um paralelo entre o conteúdo foco desta pesquisa e a figura 1, ao restringir as abordagens de ensino das atividades de croqui a zona da aprendizagem mecânica, de modo geral o resultado limita-se a memorizar padrões e símbolos gráficos, a cópias de desenhos de maneira mecanizada sem uma associação efetiva entre os elementos da paisagem e as grafias dos códigos. Assim, no momento em que são introduzidos novos desafios ou quando há uma mudança de contexto as habilidades se mostram insuficientes o que traz insegurança e até incapacidade de desenvolver as representações.

Em contrapartida, no momento em que o aprendiz perpassa a zona cinza e atinge aprendizagem significativa, há uma evolução em suas habilidades cognitivas em abstrair os elementos do ambiente e transferir suas competências às mais diversas situações desafiantes. Dentre elas podemos citar: a noção de proporção, abstração espacial, localização geográfica, insuficiências de símbolos padrões preexistentes, entre outros.

\subsubsection{Formas e tipos de aprendizagem}

A teoria ausubeliana pode ser desmembrada entre três formas: por subordinação, por superordenação e de modo combinatório.

Segundo Ausubel, a maior incidência de aprendizagem significativa é do tipo subordinada, ou seja, a nova ideia assimilada de maneira hierarquicamente subordinada à ideia preexistente (BRUM, 2014). Moreira (2010) comenta que essa forma de aprendizagem acontece quando os novos conhecimentos, potencialmente 
significativos, adquirem significados para o sujeito que aprende por um processo de ancoragem cognitiva e interativa, em relação aos conhecimentos prévios relevantes mais gerais e inclusivos já existentes na sua estrutura cognitiva.

Se o aprendiz já tem uma ideia, uma representação do que seja uma escola, a aprendizagem significativa de distintos tipos de escola como escola técnica, escola aberta, escola normal, escola pública, e outros, serão aprendidos por ancoragem e subordinação à ideia inicial de escola. Mas, ao mesmo tempo, como o processo é interativo, essa ideia inicial vai se modificando, ficando cada vez mais elaborada, mais rica e mais capaz de servir de ancoradouro cognitivo para novas aprendizagens.

Suponhamos agora que o aprendiz não tivesse uma ideia mais ampla, ou o conceito, de escola e fosse aprendendo de modo significativo o que é uma escola pública, uma escola aberta, uma escola confessional, uma escola militar, etc., ela ou ele poderia começar a fazer ligações entre diferentes tipos de escola, buscando semelhanças e diferenças e chegar, por meio de um raciocínio indutivo, ao conceito de escola. Esta seria uma aprendizagem superordenada (MOREIRA, 2010, p.14).

A aprendizagem por superordenação se dá a partir da premissa de que o novo conceito é mais geral e inclusivo que os conceitos subsunçores e condicionará o surgimento de várias ideias ocorrendo no curso do raciocínio (MOREIRA, 2010).

Por sua vez, a aprendizagem combinatória ocorre quando as ideias já estabelecidas não estão relacionadas hierarquicamente, porém se encontram no mesmo nível, não existe a relação subordinada nem superordenada (MOREIRA, 2010).

\subsubsection{Os subsunçores}

Os subsunçores são os conhecimentos prévios especificamente relevantes no processo de aprendizagem acionados na assimilação de novos conteúdos/conceitos. Podem ser proposições, modelos mentais, construtos pessoais, concepções, ideias, invariantes operatórios, representações sociais e, é claro, conceitos, já existentes na estrutura cognitiva de quem aprende (MOREIRA, 2010).

\subsubsection{Estrutura cognitiva}

De acordo com Moreira (2010) a estrutura cognitiva pode ser considerada como uma estrutura de subsunçores interrelacionados e hierarquicamente organizados. Trata-se de uma estrutura dinâmica caracterizada por dois processos principais: a diferenciação progressiva e a reconciliação integradora.

A diferenciação progressiva acontece quando há uma sucessiva utilização de um subsunçor capaz de atribuir a ele novos significados, essa mudança progressiva pode tornar o subsunçor mais estável e capaz de servir de âncora para a aquisição de novos conhecimentos (MOREIRA, 2010).

A reconciliação integradora é um processo da dinâmica da estrutura cognitiva, simultâneo ao da diferenciação progressiva, que consiste em eliminar diferenças 
aparentes, resolver inconsistências, integrar significados e fazer superordenações (MOREIRA, 2010).

A figura 2 apresenta um diagrama indicando que a diferenciação progressiva e a reconciliação integradora são interdependentes e simultâneas tanto na dinâmica da estrutura cognitiva como no ensino.

Figura 2: Diagrama da diferenciação progressiva e reconciliação integradora

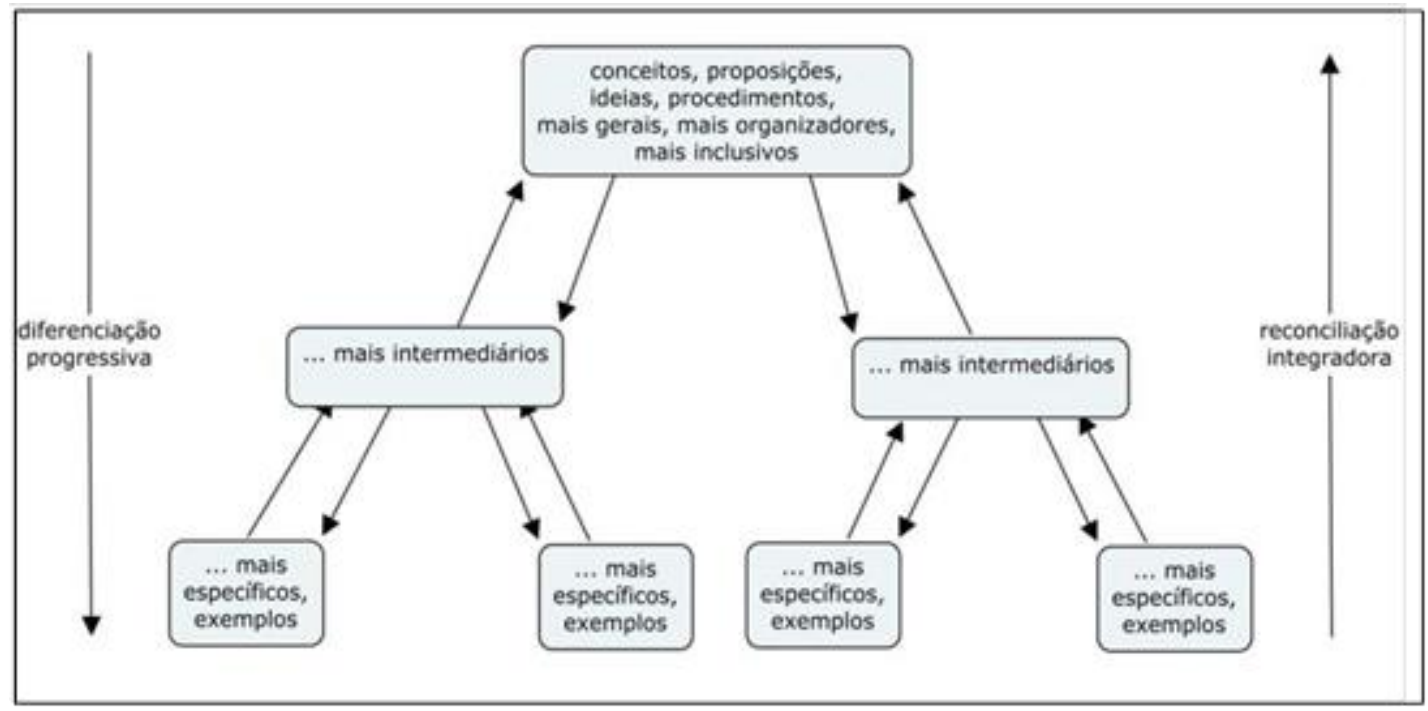

Fonte: Moreira, Mapas conceituais e aprendizagem significativa, 2010.

Além da diferenciação progressiva e da reconciliação integrativa Ausubel recomendava também o uso dos princípios da organização sequencial para facilitar a aprendizagem significativa. Segundo Ausubel, fica mais fácil para o aluno organizar seus subsunçores, hierarquicamente, se na matéria de ensino os tópicos estão sequenciados em termos de dependências hierárquicas naturais, ou seja, de modo que certos tópicos dependam naturalmente daqueles que os antecedem (MOREIRA, 2010).

\section{PROCEDIMENTOS METODOLÓGICOS}

A análise das potencialidades das atividades pedagógicas planejadas de forma interdisciplinar baseadas na teoria da aprendizagem significativa foi realizada através de uma pesquisa-ação de natureza aplicada. Segundo Thiollent (2009, p. 16) uma pesquisa ação é "um tipo de pesquisa social com base empírica que é concebida e realizada em estreita associação com uma ação ou com a resolução de um problema coletivo e no qual os pesquisadores e os participantes representativos da situação ou do problema estão envolvidos de modo cooperativo ou participativos".

Em primeiro lugar foi realizada uma pesquisa bibliográfica sobre a teoria da aprendizagem significativa de David Ausubel que norteou a construção do problema de pesquisa. Em seguida, foi elaborado um plano de ação que consistiu em desenvolver o conteúdo de Croqui Topográfico em parceria com a unidade curricular 
de Desenho Assistido por Computador, que é ofertada em paralelo no primeiro módulo do curso Técnico de Agrimensura.

O desenvolvimento do conteúdo foi organizado em três etapas de trabalho voltadas à atividade significativa subordinada. Onde inicialmente de maneira expositiva foram apresentados dos principais conceitos e analisados exemplos de croquis topográficos, em sequência ainda na primeira etapa propôs-se uma atividade prática a ser realizada extraclasse. A segunda etapa pautou-se na execução de uma atividade prática completa realizada em conjunto nas dependências do IFSC, o resultado desta atividade deu origem a etapa 3 que tratou da aplicação do croqui no desenvolvimento do desenho topográfico em CAD.

Isto posto, esta pesquisa foi realizada a partir de uma abordagem com caráter qualitativo do qual a coleta de dados se deu através de observação participante e da realização de grupos focais.

Trab (2009) define grupo focal como sendo uma forma de entrevistas em grupos, baseada na comunicação e na interação. Neste trabalho foram realizadas ao fim de cada uma das três etapas, um momento em conjunto onde os estudantes foram questionados a respeito da atividade realizada, onde buscou-se identificar suas percepções acerca de cada ação proposta.

A observação participante foi realizada nas etapas 2 e 3 . Com foco na verificação das interações dos estudantes com o conteúdo apresentado, suas manifestações durante as aulas e as tomadas de decisões na elaboração do croqui. Registradas através de transcrição das falas e anotação das observações realizadas.

Esta escolha se deve às características do tema de estudo, que envolve a investigação de estratégias didáticas que busquem o aprimoramento do aprendizado de um tema relevante na Agrimensura marcado por diversos obstáculos enfrentados pelos discentes ao desenvolver as habilidades propostas para a execução.

A turma foco da atividade realizada trata-se, dos ingressantes no primeiro módulo do curso subsequente ${ }^{2}$, onde o número total de estudantes frequentando as aulas é de 20 , dos quais $79 \%$ são do sexo masculino, a faixa etária média é de 27 anos, havendo 14 estudantes com idades entre 19 e 30 anos, e 14 com idades entre 30 e 55 anos.

Alguns dos discentes possuem formação complementar, entre as quais: técnico em edificações, arquitetura e engenharia civil. A grande maioria, no entanto, possui ensino médio sem outra formação complementar.

\section{RESULTADOS E DISCUSSÃO}

A aprendizagem mecânica ou memorística não se aplica com eficácia no aprendizado do tópico Croquis Topográficos pela dinâmica que envolve o mundo do trabalho de um profissional Técnico em Agrimensura. Cada novo levantamento implica em uma nova situação de campo completamente distinta das demais, exigindo do profissional uma nova perspectiva do ambiente a partir das análises dos elementos físicos e da aplicação do trabalho a ser realizado.

\footnotetext{
2 Os cursos técnicos subsequentes do IFSC oferecem uma formação técnica aos alunos que já concluíram o Ensino Médio
} 
Memorizar padrões de produção do croqui enfatizando mais a memória do que a própria compreensão, traz grandes limitações no processo de aprendizagem, é de suma relevância que as habilidades do desenho sejam transferíveis e adaptáveis a situações diversas.

Para tanto a proposta deste trabalho está pautada na aplicação desse conteúdo em três diferentes etapas por meio do estímulo da atividade significativa subordinada em parceria com a unidade curricular de Desenho Assistido por Computador ofertada no mesmo módulo e paralelamente ao Desenho Técnico Aplicado à Topografia.

As etapas propostas objetivam encorajar e trazer condições para a realização da aprendizagem significativa segundo Ausubel, lançando mão de um material potencialmente significativo que relacione todas as etapas.

$\mathrm{Na}$ perspectiva da aprendizagem significativa ausubeliana a estrutura cognitiva é fundamentalmente relevante, da qual o aspecto principal que mais influencia a aquisição significativa de novos conhecimentos é o conhecimento prévio (MOREIRA, 2010). A fim de se estabelecer a clareza, a estabilidade e a organização do conhecimento prévio foi utilizado um mapeamento conceitual como instrumento didático no qual houve a diferenciação progressiva e a reconciliação integrativa do conteúdo programático nas etapas de trabalho (Anexo 1).

Uma vez introduzidos os conceitos e proposições mais gerais do tema foram apresentados alguns exemplos e a proposta da atividade na primeira etapa. Na qual cada participante foi estimulado a confeccionar o croqui topográfico de seus respectivos ambientes ${ }^{3}$, nele deveria conter a representação da edificação, os limites do terreno (quando houver) e o mapa de localização englobando as ruas adjacentes, pontos de referência e elementos de orientação.

Por se tratar de uma escolha por familiarização, este deveria ser possivelmente um lugar seguro, onde se localizam geograficamente com mais facilidade em relação a outros pontos da cidade, que já conhecem a forma, os elementos físicos e as relações topológicas existentes entre eles.

Ao final da primeira etapa foi realizado o primeiro grupo focal no qual foi identificado que alguns dos estudantes não realizaram a atividade, alguns realizaram de forma mecânica e, portanto, insatisfatória, outros, no entanto, demonstraram maior interesse. Esta foi uma atividade efetuada fora do ambiente escolar, e possivelmente por isso, em seus relatos foi identificado que a maioria dos que não realizaram, alegaram não terem tido tempo devido aos compromissos diários, alguns demonstraram desinteresse tendo esquecido da tarefa.

Algumas falas demonstraram insegurança dos alunos no processo de produção do croqui, relatando que não sabiam por onde começar o desenho ou até mesmo que precisavam refazê-lo várias vezes até conseguirem representar todos os elementos necessários. Este pode ser um indicativo de que a autonomia necessária nesta etapa ainda não havia sido atingida com unanimidade nas aulas iniciais. Embora alguns alunos tenham realizado a atividade sem grandes dificuldades, eventualmente a mesma poderia ter melhor resultado como segunda etapa.

\footnotetext{
${ }^{3}$ Foi dada a opção de escolha do ambiente em que se sentissem mais à vontade, podendo ser suas casas, trabalho, lugar de lazer, entre outros.
} 
No entanto no que diz respeito ao resultado produzido pelo estudante $(\mathrm{O}$ croqui), nesta etapa da atividade, não existe certo ou errado, o objetivo é desenvolver a percepção do espaço físico e a abstração dos elementos pertencentes ao espaço que são relevantes a representação de um croqui topográfico, além da percepção do ambiente visto em planta.

A segunda etapa foi a realização do croqui topográfico de um terreno simulado nas instalações do IFSC, o mesmo contendo um limite bem definido, uma edificação de alvenaria e ainda alguns detalhes importantes como árvores, postes e luminárias. Desta vez foi introduzida na atividade o componente ponto topográfico, ao qual é preciso atribuir um nome que deve ser unívoco e será associado posteriormente a uma medida de distância e direção. Como facilitador deste processo foram utilizadas placas com o nome dos pontos fixadas no terreno e em cada um dos elementos físicos desenhados. Os processos de orientação e localização foram realizados em conjunto.

A tomada de decisão no que tange a escolha de quais seriam os pontos relevantes a representação do terreno foi feita em conjunto com enfoque na relação entre o ponto e o desenho topográfico. da etapa 3.

Os mesmos nomes que foram alvo da identificação no papel serão conectores

No que diz respeito aos obstáculos relatadas nesta segunda etapa, no segundo grupo focal os participantes foram unânimes em assumir que ainda houveram algumas dificuldades, no entanto já se sentiram mais seguros na execução.

As tomadas de decisão a respeito de detalhes como por onde iniciar o desenho ou como orientar o terreno em relação ao papel, aconteceu de maneira mais orgânica tendo sido o desenvolvimento mais inteligível que na etapa 1. Diferente da etapa anterior houve uma valorização dos desenhos produzidos facilmente identificados em suas colocações. O que demonstra a importância da mediação do professor para a eficácia da aprendizagem nestas etapas iniciais.

A evolução dos alunos foi percebida tanto no resultado do desenho como na utilização de termos afirmativos em suas sentenças ao descrever o processo realizado.

A terceira etapa se tratou do desenho topográfico no ambiente computacional, realizado na unidade curricular de CAD. Foi utilizado o mesmo terreno simulado da etapa 2 com os mesmos nomes para os pontos. O professor da unidade utilizou dados de medição anteriormente coletados pelos próprios alunos e o croqui com as mesmas características. Foi desenvolvida a atividade com enfoque na importância da escolha de cada ponto topográfico para que fosse possível, a partir das medições, a representação fidedigna do terreno e dos detalhes topográficos a ele pertencentes. A associação das medidas aos elementos do desenho foi realizada pela nomenclatura dos pontos.

No momento da realização da atividade os alunos reconheceram de imediato o ambiente que trabalharam, o terreno e suas características. Foram introduzidos os comandos do software é produzido o desenho utilizando as medidas de campo e buscando sua significação no croqui (Figura 3). 
Figura 3: Registro das etapas 2 e 3 realizadas nas unidades curriculares de CAD e DET

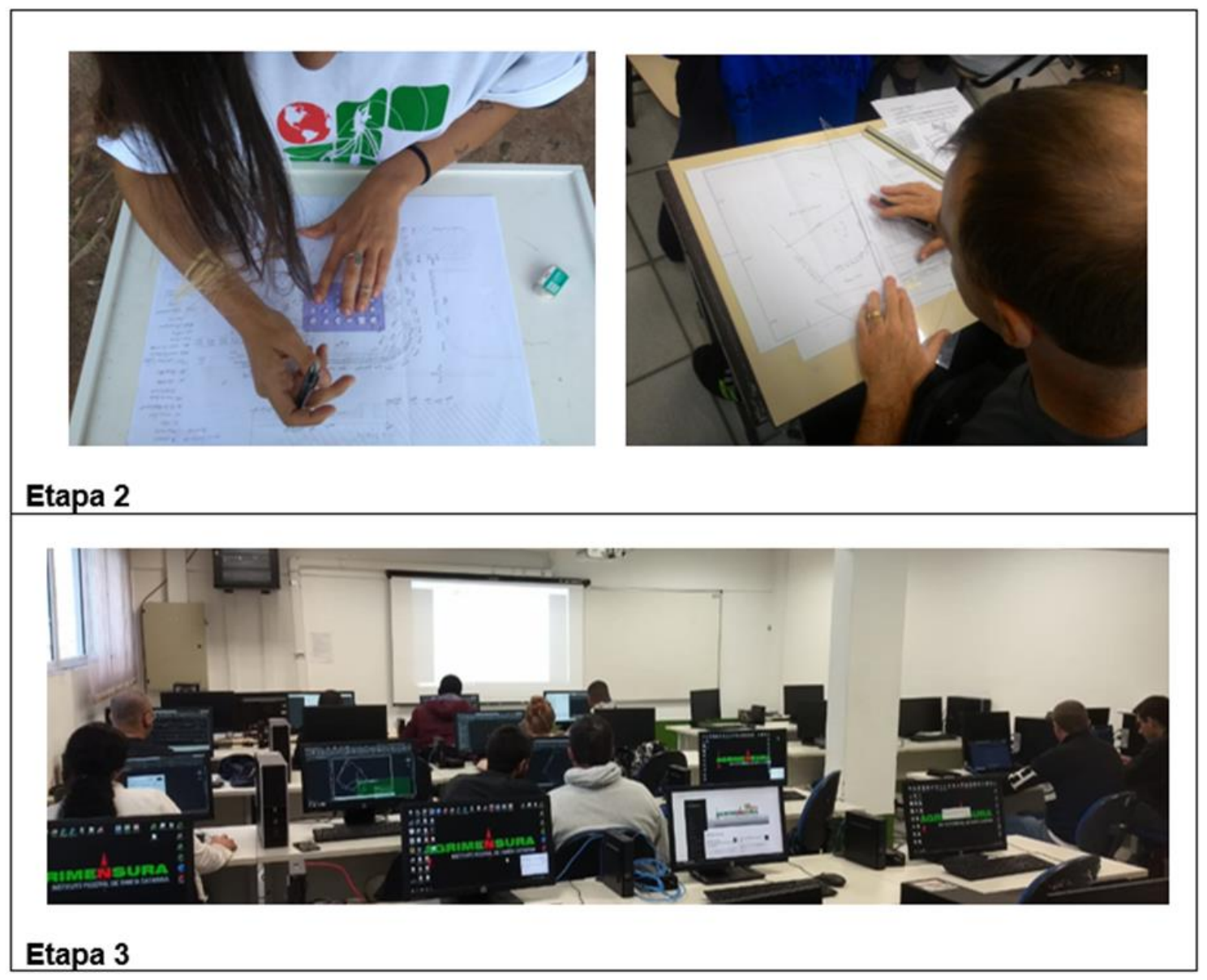

Fonte: Autores (2019).

Nesta atividade o croqui passou a ser subsunçor do desenho topográfico, ao passo que o desenvolvimento do desenho topográfico reforçou a relevância dos conceitos apresentados para a execução do croqui. Estes processos são simultâneos, da dinâmica da estrutura cognitiva.

Quando o croqui assume o significado do subsunçor ao mesmo tempo fica mais rico em significados, pois ele agora além da representação do espaço dará significado às medições espaciais e ao desenho topográfico em si.

A resultante da sucessiva utilização do croqui para dar significado ao resultado das medições e a elaboração do desenho final pode trazer uma diferenciação progressiva como processo de atribuição de novos significados ao subsunçor, já que, as tomadas de decisão no momento da elaboração do croqui em campo passam a ter relação com as necessidades específicas de elaboração do desenho topográfico no ambiente computacional.

Esses aspectos ficaram evidentes nas colocações dos alunos no terceiro e último grupo focal, quando relataram ter entendido de maneira mais clara o papel de cada ponto topográfico no trabalho como um todo. Evidenciaram acreditar serem capazes, a partir de então, a pensar quais são os melhores pontos a se coletar que fariam com que o desenho se tornasse mais completo e eficiente. 
Embora a abordagem do conteúdo tenha sido realizada em um ambiente relativamente simples, alguns alunos demonstraram dificuldades em relacionar a proporção dos elementos físicos do terreno e a topologia dos mesmos.

A relação entre o elemento real e sua representação no papel através da simbologia tornou-se um processo mais natural com a introdução das placas com nome dos pontos fisicamente no terreno e não somente de modo verbal.

A participação e a integração dos estudantes com as atividades foram maiores nas etapas 2 e 3 , aqueles que realizaram a etapa 1 se mostraram substancialmente mais preparados e familiarizados com as demais atividades.

Inúmeras condições impostas pelas características da profissão trazem a necessidade de lidar com diferentes ambientes e situações dinâmicas as quais a aplicação dos conhecimentos adquiridos depende de criatividade e adaptação, ainda que a característica da grande maioria das unidades curriculares do curso seja essencialmente composta por aulas práticas, não há uma forma por meio da simples memorização de capacitá-los para todas as situações que encontraram. Neste sentido a aprendizagem significativa pode trazer relevantes ferramentas que contribuam na construção do conhecimento.

\section{CONSIDERAÇÕES FINAIS}

Ao inserir os princípios teóricos da aprendizagem significativa no ensino do Croqui topográfico na unidade curricular de Desenho Assistido por Computador, percebe-se que o mesmo pode tornar-se um subsunçor ao mesmo tempo que assumiu uma posição na reconciliação integradora ao provocar o olhar dos alunos para as relações espaciais e aplicações do croqui dentro no desenho topográfico, respondendo à questão fundamental da presente pesquisa.

A organização sequencial das atividades e habilidades utilizadas na sua aplicação evidenciou as características e os obstáculos encontrados pelos estudantes na relacionalidade e a discriminabilidade entre conhecimentos prévios e novos conhecimentos. A estratégia didática integradora presente nas três etapas de trabalho foi um facilitador do qual a interdisciplinaridade foi a característica que mais enriqueceu a associação entre os conhecimentos estudados.

Essencialmente, são duas as condições para a aprendizagem significativa: 0 material de aprendizagem deve ser potencialmente significativo e o aprendiz deve apresentar uma predisposição para aprender (MOREIRA, 2010). Estas particularidades ficaram evidentes nos grupos focais realizados ao final de cada etapa nas colocações trazidas pelos estudantes. Identificou-se que a primeira atividade exigiu um grau de autonomia que alguns deles ainda não haviam atingido, isso poderia ser remediado repensando as premissas desta tarefa ou realizando-a em outro momento, como segunda ou terceira etapa. Apesar disso, foi notória a evolução na autonomia de trabalho ao longo das etapas, em especial daqueles que demonstraram maior predisposição e abertura à aprendizagem.

Por fim é importante ressaltar que os significados e conceitos adquiridos nesta atividade devem ser enfatizados e reavivados oportunamente ao longo da formação do Técnico Agrimensor. 


\section{REFERÊNCIAS}

Associação Brasileira de Normas Técnicas (ABNT). NBR 13133: Execução de levantamento topográfico. Rio de Janeiro, 1994. 35p.

AURÉLIO, O minidicionário da língua portuguesa. $4^{\text {a }}$ edição revista e ampliada do minidicionário Aurélio. $7^{\underline{a}}$ impressão - Rio de Janeiro, 2002.

BARCELOS, Bartholomeo; ALLAIN, Olivier; WOLLINGER, Paulo. Livro 1:

Fundamentos da Didática e Didática Profissional. 2017. Material de Aula sistema. Moodle. Disponível em: Acesso em: 10 dez. 2017.

BRUM, Wanderley Pivatto. Aprendizagem Significativa: Revisão teórica e apresentação de um instrumento para aplicação em sala de aula. 2014. Itinerarius Reflectionis, 9(2). https://doi.org/10.5216/rir.v2i15.27795.

MOREIRA, Marco Antonio. $O$ que é afinal aprendizagem significativa? Aula Inaugural do Programa de Pós-Graduação em Ensino de Ciências Naturais, Instituto de Física, Universidade Federal do Mato Grosso, Cuiabá, MT, 23 de abril de 2010. Aceito para publicação, Qurriculum, La Laguna, Espanha, 2012.

MOREIRA, Marco Antonio. Mapas conceituais e aprendizagem significativa. São Paulo: Centauro, 2010.

TRAD, Leny A. Bomfim. Grupos focais: conceitos, procedimentos e reflexões baseadas em experiências com o uso da técnica em pesquisas de saúde. Physis, Rio de Janeiro, v. 19, n. 3, p. 777-796, 2009. Available from <http://www.scielo.br/scielo.php?script=sci_arttext\&pid=S0103-

$73312009000300013 \& \operatorname{lng}=$ en\&nrm $=$ iso $>$. access on 13 Feb. 2019. http://dx.doi.org/10.1590/S0103-73312009000300013.

THIOLLENT, Michel. Metodologia de Pesquisa-ação. São Paulo: Saraiva. 2009. VEIGA, Luis Augusto Koenig; ZANETTI, Maria Aparecida Zehnpfennig; FAGGION, Pedro Luis. Fundamentos de topografia. 2012. Disponível em:<http://www.cartografica.ufpr.br/docs/topo2/apos_topo.pdf> Acesso em: 06 set. 2018. 
Revista Brasileira da Educação Profissional e Tecnológica, v. 1, n. 20, e8460, 2021, p. 14 de 14 CC BY 4.0 | ISSN 2447-1801 | DOI: https://doi.org/10.15628/rbept.2021.8460

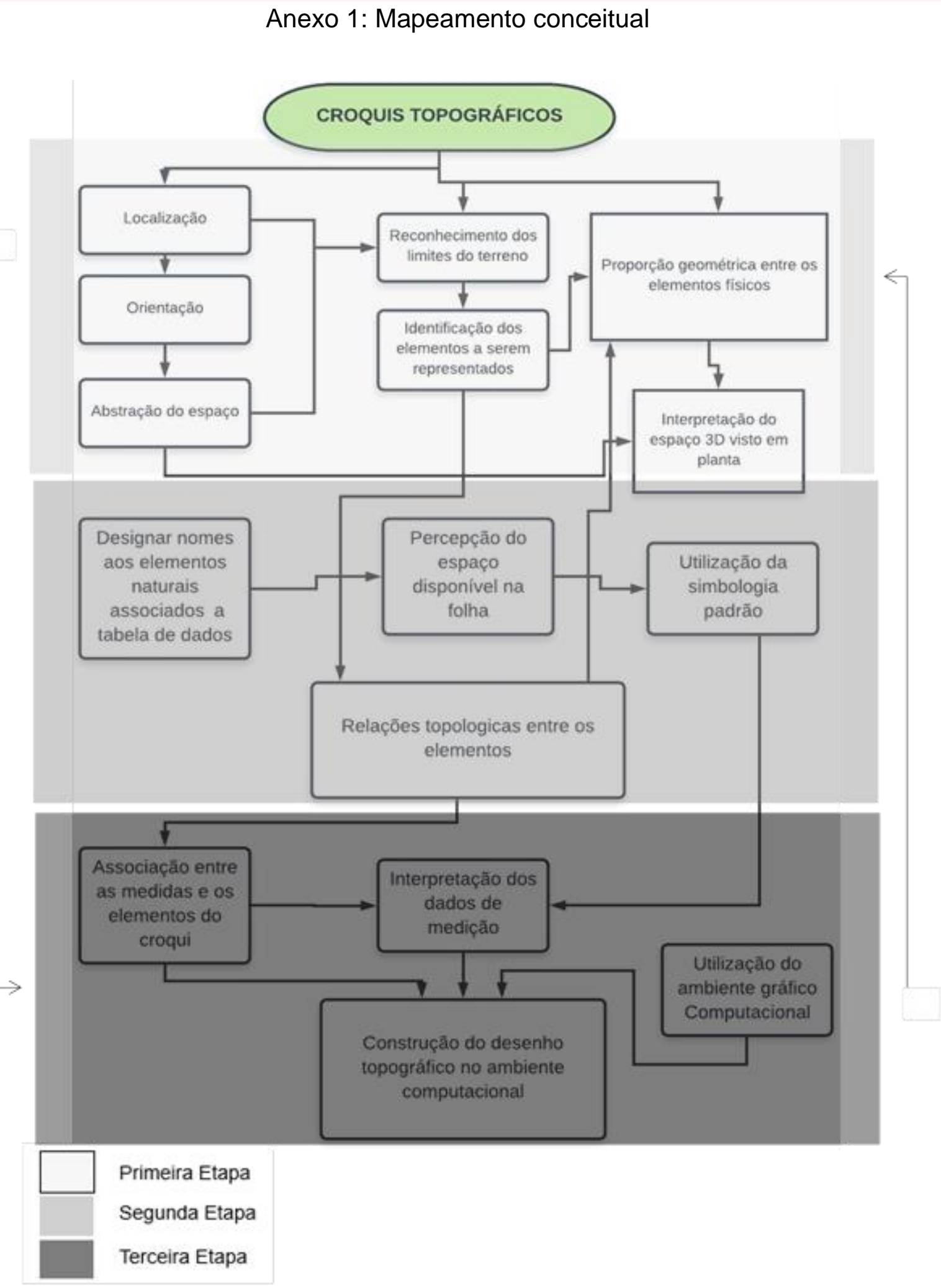

Fonte: Desenvolvido pelas autoras (2019). 